\title{
Atividade proteolítica e crescimento de matrinxã em natação sustentada e alimentado com dois níveis de proteína
}

\author{
Gustavo Alberto Arbeláez-Rojas ${ }^{(1)}$, Luís Antônio Kioshi Aoki Inoue ${ }^{(2)}$ e Gilberto Moraes ${ }^{(1)}$ \\ (1)Universidade Federal de São Carlos, Departamento de Genética e Evolução, Laboratório de Bioquímica Adaptativa, CEP 13565-905 São \\ Carlos, SP. E-mail: matamba2@yahoo.com.br, gil@ufscar.br ${ }^{(2)}$ Embrapa Amazônia Ocidental. Rodovia AM 10, Km 29, Zona Rural, \\ CEP 69010-970 Manaus, AM. E-mail: luis.inoue@cpaa.embrapa.br
}

\begin{abstract}
Resumo - O objetivo deste trabalho foi avaliar o efeito da natação sustentada sobre a atividade digestiva proteolítica e o crescimento de juvenis de matrinxã (Brycon amazonicus), alimentados com dois níveis de proteína. Foram utilizados 240 peixes, tratados com 28 ou $38 \%$ de proteína bruta (PB), durante 60 dias, em duas situações distintas: em natação sustentada à velocidade de uma vez e meia o comprimento corporal por segundo, e em sistema convencional de cultivo, sem movimento forçado. Os peixes em natação sustentada e alimentados com $28 \%$ de PB apresentaram melhor desempenho, expresso como maior crescimento, alta taxa de crescimento específico, maior ganho de peso e melhor eficiência alimentar. A natação sustentada proporcionou aumento significativo da atividade digestiva proteolítica alcalina, proporcional ao conteúdo de proteína na dieta. Juvenis de matrinxã alimentados com dietas com $28 \%$ de PB e em natação sustentada apresentam melhor aproveitamento dos nutrientes como consequência de ação proteolítica digestiva mais efetiva.
\end{abstract}

Termos para indexação: Brycon amazonicus, deposição proteica, enzima digestiva, exercício físico, protease, proteína corporal.

\section{Proteolytic activity and growth of matrinxã at sustained swimming speed and fed two protein levels}

\begin{abstract}
The objective of this work was to evaluate the effect of sustained swimming speed on the proteolytic digestive activity and growth performance of matrinxã (Brycon amazonicus) juveniles, fed two protein levels. Two-hundred and forty fish were used, fed with 28 or $38 \%$ of crude protein (CP) during 60 days, in two different situations: sustained swimming at a speed of 1.5 times the body length per second and in a conventional cultivation system, without forced movement. Fish at sustained swimming and fed $28 \%$ CP showed the best performance, expressed as greater growth, higher specific growth rate, greater weight gain and improved feed efficiency. Sustained swimming provided a significant increase in the activity of alkaline proteolytic digestion, proportional to the protein level in the diet. Matrinxã juveniles fed diets with $28 \% \mathrm{CP}$ and under sustained swimming conditions showed better nutrient assimilation, as a consequence of a more effective proteolytic digestive action.
\end{abstract}

Index terms: Brycon amazonicus, protein deposition, digestive enzyme, physical exercise, protease, body protein.

\section{Introdução}

Durante o ciclo de vida dos peixes, a maior taxa de crescimento é observada entre as fases larval e juvenil, quando a taxa de síntese de proteína excede a de degradação. Esse processo é mais acentuado em músculos natatórios, onde há alta eficiência de deposição proteica (Carter \& Houlihan, 2001). Nessa fase, esses músculos podem atingir até $70 \%$ de eficiência de deposição, enquanto no corpo como um todo esse índice varia entre 40 e 50\% (Jobling, 2001). A natação sustentada pode exacerbar essas respostas orgânicas, ao estimular o aumento de proteína corporal (crescimento) e melhorar sua eficiência de deposição, mesmo havendo maior gasto energético em razão do aumento de contrações musculares (Jobling et al., 1993; Davison, 1997; Hackbarth \& Moraes, 2006).

A suposição de que peixes criados em ambientes de correnteza tinham seu crescimento prejudicado, pelo fato de que muita energia seria desviada para atender à demanda energética imposta pela atividade física, era amplamente difundida entre os aquicultures (Jobling et al., 1993). Pensava-se que a diminuição da natação ao seu máximo possível resultaria em mais energia alocada para o crescimento (Pitcher \& Hart, 1982). A base dessa concepção são os altos níveis de energia requeridos para a manutenção dos peixes em natação contra a corrente, que reduziriam as taxas de 
crescimento e aumentariam os custos com a alimentação (Jobling et al., 1993). No entanto, atualmente, há evidência de que o exercício conduzido de forma moderada traz efeitos benéficos aos peixes, quer em nível fisiológico, morfológico ou comportamental. Salmonídeos criados por longos períodos em natação sustentada, a velocidades menores que 2,0 $\mathrm{CC} \mathrm{s}^{-1}$ (comprimento corporal por segundo), apresentam taxas de crescimento superiores àqueles sedentários, criados em ambientes de água lêntica (Totland et al., 1987; Christiansen \& Jobling, 1990; Jobling et al., 1993; Davison, 1997).

Embora a natação sustentada estimule o apetite dos peixes, tem-se observado melhora na eficiência da conversão alimentar, o que indica maior aproveitamento dos nutrientes da dieta (Christiansen \& Jobling, 1990; Jobling et al., 1993). No entanto, muitas são as lacunas, ainda, no conhecimento dos processos que se seguem à ingestão dos nutrientes, como a digestão, a absorção e a assimilação. Ao nosso conhecimento, não há informação da literatura sobre repostas adaptativas de enzimas digestivas em consequência do exercício físico e sobre possíveis interações entre composição da dieta e exercício. $\mathrm{Na}$ tentativa de se adequar ao aumento da demanda fisiológica, causada tanto pelo exercício quanto pela alteração da dieta, os peixes aumentam sua capacidade cardiorrespiratória ( $\mathrm{Li}$ et al., 2010), para suprir a exigência de oxigênio e a demanda de nutrientes requerida pelos processos de contração muscular e de digestão.

O matrinxã, Brycon amazonicus (Spix \& Agassiz, 1829), é uma espécie neotropical de água doce, nativa das bacias Amazônica e Tocantins-Araguaia (Howes, 1982). Essa espécie tem grande potencial para a aquicultura, pois apresenta taxas de crescimento desejáveis, ótimo crescimento em condições de cativeiro, alta qualidade e sabor de carne, além de suportar altas densidades de estocagem (Brandão et al., 2005; Arbeláez-Rojas \& Moraes, 2009). Na Amazônia Ocidental, cultivos de matrinxãs já são presentes em condições de natação sustentada, em canais adaptados em igarapés (Arbeláez-Rojas et al., 2002).

O objetivo deste trabalho foi avaliar o efeito da natação sustentada sobre a atividade proteolítica digestiva total e o desempenho produtivo de juvenis de matrinxã, alimentados com dietas com dois níveis de proteína.

\section{Material e Métodos}

O experimento foi realizado de março a maio de 2009, no Departamento de Genética e Evolução da Universidade Federal de São Carlos $\left(22^{\circ} 1^{\prime} 4^{\prime \prime} S\right.$, $47^{\circ} 23^{\prime} 57^{\prime \prime} \mathrm{W}$, à altitude de $860 \mathrm{~m}$ ), em clima tropical de altitude, com juvenis de matrinxã. Antes do experimento, os peixes foram aclimatados em sistema de recirculação de água, durante três semanas. No período de aclimatação, a temperatura da água foi mantida a $27 \pm 0,5^{\circ} \mathrm{C}$, e o conteúdo de oxigênio ficou acima de $5 \mathrm{mg} \mathrm{L}^{-1}$. Os peixes foram alimentados quase à saciedade, por três vezes ao dia, com ração comercial $\left(36 \%\right.$ PB e $\left.4.298 \mathrm{kcal} \mathrm{kg}^{-1}\right)$. Ao final do período de aclimatação, 240 juvenis de matrinxã foram selecionados, com peso e comprimento médios de $29,5 \pm 1,32 \mathrm{~g} \mathrm{e} 13 \pm 1,2 \mathrm{~cm}$, respectivamente. Esses peixes foram separados e transferidos, aleatoriamente, para 12 caixas circulares de fibra de vidro, com volume de $250 \mathrm{~L}$, à densidade final de 20 peixes por caixa, mantidos em sistema fechado, com água termostatizada à temperatura de $28^{\circ} \mathrm{C}$, sob fluxo contínuo e aeração constante.

Os peixes foram alimentados com dietas com 28 ou 38\% de proteína bruta e comparados em duas situações distintas: em natação sustentada e em sistema convencional de água parada, com três repetições, pelo período experimental de 60 dias. Em seis caixas, os peixes foram mantidos em natação sustentada contra a correnteza, à velocidade de $1,5 \mathrm{CC} \mathrm{s}^{-1}$ (grupo de natação sustentada). Nas outras seis caixas, os peixes foram mantidos em água sem correnteza ou parada (grupo sedentário). Nas caixas com correnteza, a velocidade da água foi gerada e regulada através de fluxo gerado por uma bomba Mark NXDP4 (Bombas Grundfos do Brasil Ltda., São Bernardo do Campo, SP, Brasil), com entrada e saída de 1", e 1 cv de potência. A velocidade da água, em cada tanque, foi aferida e ajustada, a cada três semanas, com um fluxômetro mecânico (General Oceanics Inc. Miami, FL, USA). A velocidade de natação de $1,5 \mathrm{CC} \mathrm{s}^{-1}$ foi selecionada com base em estudos realizados por Arbeláez-Rojas \& Moraes (2010).

Ambos os grupos foram alimentados quase à saciedade aparente, por três vezes ao dia, às 9,13 e $17 \mathrm{~h}$, com dietas extrusadas e isocalóricas de 4,1 kcal kg-1, com dois níveis de PB: 28 e 38\% (Tabela 1). As dietas foram formuladas e fabricadas no Laboratório de Bioquímica Adaptativa da Universidade Federal de São 
Carlos. A análise bromatológica das dietas foi realizada no Laboratório de Nutrição Animal do Departamento de Zootecnia da Faculdade de Ciências Agrárias e Veterinárias da Universidade Estadual Paulista, Campus de Jaboticabal, conforme a Association of Official Analytical Chemists (Cunnif, 1995).

A cada três semanas, foram realizadas biometrias de todos os peixes das 12 caixas, quando também foi ajustada a quantidade de ração oferecida. Ao final do período experimental, os peixes permaneceram em jejum por 24 horas, para esvaziamento gástrico e, em seguida, foi realizada a última biometria. Antes das pesagens, os peixes foram anestesiados com óleo de cravo, previamente diluído em etanol e ajustado para a concentração final de $40 \mathrm{mg} \mathrm{L}^{-1}$ (Inoue et al., 2003). A pesagem dos peixes, em cada tratamento, foi feita em

Tabela 1. Composição centesimal das dietas experimentais para matrinxã, com base na matéria natural.

\begin{tabular}{|c|c|c|}
\hline \multirow[t]{2}{*}{ Ingredientes } & \multicolumn{2}{|c|}{ Nível de proteína na dieta (\%) } \\
\hline & 28 & 38 \\
\hline$\overline{\text { Farinha de peixe }}{ }^{(1)}$ & 23,50 & 32,00 \\
\hline Farelo de soja $48^{(2)}$ & 18,00 & 32,68 \\
\hline Milho $^{(3)}$ & 51,48 & 28,30 \\
\hline Quirera de $\operatorname{arroz}^{(4)}$ & 3,00 & 3,00 \\
\hline Levedura & 1,00 & 1,00 \\
\hline Óleo de soja $\mathrm{a}^{(5)}$ & 1,00 & 1,00 \\
\hline Sal & 0,02 & 0,02 \\
\hline Vitamina mineral Premix ${ }^{(6)}$ & 2,00 & 2,00 \\
\hline Total & 100 & 100 \\
\hline Parâmetro & \multicolumn{2}{|c|}{ Composição calculada } \\
\hline Matéria seca (MS, \%) & 88,63 & 88,99 \\
\hline Energia bruta $\left(\mathrm{EB}, \mathrm{kcal} \mathrm{kg}^{-1}\right)$ & $3.920,1$ & $3.981,1$ \\
\hline Proteína bruta (PB, \%) & 28,01 & 38,00 \\
\hline Carboidratos $(\%)(\mathrm{F})$ & 44,98 & 32,84 \\
\hline Fibra bruta $(\mathrm{FB}, \%)$ & 2,22 & 2,57 \\
\hline Matéria mineral (MM, \%) & 6,64 & 8,86 \\
\hline Extrato etéreo (EE, \%) & 4,83 & 4,77 \\
\hline Cálcio $(\mathrm{Ca}, \%)$ & 1,15 & 1,57 \\
\hline Fósforo (P, \%) & 0,81 & 1,06 \\
\hline Vitamina C (\%) & 0,05 & 0,05 \\
\hline
\end{tabular}

${ }^{(1)}$ Composição em percentagem: MS, 90,4; MM, 20,86; EE, 5,85; FB, 3,6; PB, 60,0; Ca, 4,45; P, 2,41; EB, $3.795 \mathrm{cal} / \mathrm{g} .{ }^{(2)} \mathrm{MS}, 8,22 ; \mathrm{MM}$, 5,17; EE, 2,38; PB, 47,76; Ca, 0,03; P, 0,06. ${ }^{(2)} \mathrm{MS}, 87,45$; MM, 1,35; $\mathrm{EE}, 3,9$; FB, 2,17; PB, 9,13; Ca, 0,03; P, 0,24; e EB, 4.226 cal g-1 ${ }^{-1}{ }^{(3)} \mathrm{MS}$, 88,56; PB, 8,59; EE 8,3; FB;4,5; Ca, 0,97; P, 0,14. ${ }^{(4)} \mathrm{EB}, 9.811 \mathrm{cal} \mathrm{g}^{-1}$. ${ }^{(5)}$ Calculado como \% MS-(PB+EE+MM+FB) ${ }^{(6)}$ Composição do suplemento vitamínico mineral para peixes Premix, níveis de garantia por $1.000 \mathrm{~g}$ : vitamina A, 600.000 IU; vitamina D3, $600.000 \mathrm{IU}$; vitamina E, $12.000 \mathrm{IU}$; vitamina K3, $1.200 \mathrm{mg}$; vitamina B1, $1.200 \mathrm{mg}$; vitamina B2, $1.536 \mathrm{mg}$; vitamina B6, $1.287 \mathrm{mg}$; vitamina B12, $4.000 \mathrm{mg}$; ácido fólico, $198 \mathrm{mg}$; ácido pantotênico, $3.800 \mathrm{mg}$; vitamina C, $48.000 \mathrm{mg}$; biotina, $20 \mathrm{mg}$; colina, $30.000 \mathrm{mg}$; niacina, $19.800 \mathrm{mg}$; Fe $25.714 \mathrm{mg}$; Cu $1.960 \mathrm{mg}$; Mn 13.334 mg; Zn 6.000 mg; 1. 948 mg; Co 2 mg; Se 30,10 mg. balança digital marca Acculab V-1200, com uma casa decimal de precisão, e o comprimento total dos peixes foi medido em régua graduada, em mm. Após a última biometria, os peixes foram sacrificados para retirada do sistema gastrointestinal, o qual foi dissecado, imerso em solução salina a $0,1 \%$ gelada, em placa de Petri sobre gelo, e seccionado em quatro frações: estômago, cecos pilóricos, e intestino anterior e posterior. Em seguida, essas frações foram congeladas em nitrogênio liquido e transferidas para congelador a $-20^{\circ} \mathrm{C}$, para posteriores ensaios enzimáticos.

Para determinar a atividade enzimática das proteases inespecíficas, foram retiradas amostras de aproximadamente $100 \mathrm{mg}$ de tecido por peixe, transferidas para tampão (glicerol em tampão fosfato de sódio $20 \mathrm{mmol} \mathrm{L}-1 /$ Tris $10 \mathrm{mmol} \mathrm{L}^{-1}$, $\mathrm{pH} 7,0 \mathrm{v} / \mathrm{v}$ ) e homogeneizadas em homogeneizador tipo Potter-Elvehjem a $1.000 \mathrm{rpm}$, por aproximadamente dois min, sob banho de gelo. O homogeneizado celular de estômago foi centrifugado a $13.400 \mathrm{~g}$, por $3 \mathrm{~min}$, e o de cecos pilóricos, intestino anterior e posterior, por $6 \mathrm{~min}$. Os sobrenadantes foram utilizados como fonte de enzima. As quantidades de sobrenadante, utilizadas nos ensaios enzimáticos, foram determinadas na etapa de padronização e ajustadas para valores adequados por ensaio.

A atividade proteolítica total foi testada pelo método de hidrólise da caseína, adaptado por Hidalgo et al. (1999), e o teor de aminoácidos livres foi determinado no sobrenadante a $280 \mathrm{~nm}$. A atividade proteolítica do estômago foi testada em tampão $\mathrm{pH} 2,0$, e a de cecos pilóricos e intestino anterior e posterior em tampão $\mathrm{pH}$ 9,0. Uma unidade de enzima (UI) foi definida como a quantidade necessária para formar $1 \mu \mathrm{g}$ de tirosina por min. A atividade específica está expressa em UI por mg de proteína.

O teor total de proteína das porções do trato digestório foi determinado pelo método de Bradford, a $450 \mathrm{~nm}$ (Kruger, 2002), contra um padrão de albumina a $1 \mathrm{mg} \mathrm{mL}^{-1}$ lida em em um ThermoMax Microplate Reader a $450 \mathrm{~nm}$ (Molecular Devices, Sunnyvale, CA, EUA).

O glicogênio foi determinado segundo Bidinotto et al. (1997). O método baseia-se na hidrólise ácida do glicogênio, quantificado pela determinação do teor de açucares redutores totais a $480 \mathrm{~nm}$, contra um padrão de glicose a $1 \mathrm{mmol} \mathrm{L}^{-1}$ (Dubois et al., 1956). O teor de glicogênio está expresso em $\mu \mathrm{mol}$ de glicosil-glicose por mg de tecido. 
A avaliação do desempenho produtivo dos peixes foi baseada no consumo de ração e nas biometrias das unidades experimentais de cada tratamento. Foram calculados os parâmetros: consumo diário de ração, $\mathrm{CDR}=$ consumo de alimento/tempo (em dias); conversão alimentar aparente, CAA = consumo de alimento/ganho em peso; taxa de crescimento específico, $\mathrm{TCE}=(\ln$ peso final $-\ln$ peso inicial $) \times 100 /$ tempo; e taxa de eficiência proteica, TEP = ganho em peso vivo/proteína bruta consumida. Também foram determinados os índices morfométricos. Para tanto, ao final do experimento, após o jejum de 24 horas, 10 peixes de cada unidade experimental foram coletados, anestesiados (40 $\mathrm{mg} \mathrm{L}^{-1}$ de eugenol) e abatidos. Em seguida, foram retirados $\mathrm{o}$ fígado e a gordura visceral dos peixes, para a determinação dos índices hepato-somático (IHS) e gorduro-víscero-somático (IGVS), a partir da expressão IHS ou IGVS $=100$ x peso do tecido/peso corporal, e do fator de condição (FC), a partir da expressão $\mathrm{FC}=$ peso/(comprimento $)^{3}$.

Empregou-se o delineamento inteiramente casualizado, em esquema fatorial $2 \times 2$, com dois níveis de proteína na dieta (28 e $38 \%$ de PB) e duas condições de criação (peixes exercitados e não exercitados), com três repetições. Os dados foram analisados quanto à variância pelo teste "two-way" ANOVA e, quando as diferenças foram significativas, as médias dos tratamentos foram comparadas pelo teste de Tukey, a 5\% de probabilidade.

\section{Resultados e Discussão}

Os peixes alimentados com $28 \%$ de $\mathrm{PB}$ e submetidos à natação sustentada apresentaram $\mathrm{PF}$, taxa de crescimento específico e ganho de peso diário superior, em comparação aos demais tratamentos (Tabela 2). Tem-se observado que o exercício de natação sustentada em peixes estimula o crescimento e o ganho de peso, e apresenta vantagens sobre o sistema tradicional de criação em água estacionária (Davison, 1997; Hackbarth \& Moraes, 2006; Arbeláez-Rojas \& Moares, 2010).

Considerando-se que os exemplares de matrinxã utilizados neste trabalho pertenciam à mesma prole, pode-se inferir que os tratamentos tenham sido as principais responsáveis pelos resultados obtidos. No entanto, um fator de origem constitutiva (genotípico) que pode ter contribuído para os resultados é a forma corporal do matrinxã. Sua estrutura fusiforme, com cauda em forma crescente e pedúnculo estreito, tipifica uma das suas melhores adaptações morfológicas à locomoção aquática. Essa característica vantajosa ao matrinxã reduziria o custo energético da locomoção, o que pouparia energia para o crescimento (Arbeláez-Rojas et al., 2002).

A conversão alimentar aparente foi afetada tanto pela condição de criação quanto pelo nível da proteína da dieta (Tabela 2). Peixes em nado sustentado apresentaram CAA maior do que os sedentários. Ainda, peixes alimentados com $38 \%$ de $\mathrm{PB}$ apresentaram CAA maior que os alimentados com $28 \%$ de PB. Esse parâmetro relaciona o consumo de alimento com o ganho de peso. Vários fatores podem afetá-lo; entre eles, o sistema de produção, a qualidade da água e a composição e qualidade do alimento (Jobling, 2001). Além desses, a velocidade da água pode afetar o consumo de ração e, indiretamente, a CAA. Velocidades excessivas diminuem a capacidade dos peixes em capturar a ração e afetam o consumo de alimento (Jobling, 2001). A criação sob correntezas moderadas facilita a captura da ração e melhora sua distribuição. Isso reduz a agressividade potencial da busca pelo alimento. Portanto, velocidades de água moderadas, nos sistemas de criação, apresentam várias vantagens e podem contribuir até para a auto limpeza dos criadouros.

Ainda que a criação de algumas espécies de peixes em sistemas de natação sustentada mostre vantagens, sua aplicação em sistemas de longa duração traria duplo aumento da demanda energética (Carter \& Houlihan, 2001). Dessa forma, o exercício aceleraria o crescimento, por meio do estímulo à síntese proteica e à hipertrofia das fibras musculares (Totland et al., 1987), mas também aumentaria a contração muscular em resposta ao esforço físico. Ambos os processos demandam energia, o que acelera o metabolismo e aumenta o apetite. De fato, salmonídeos e outras espécies demersais mostram, claramente, que o aumento do crescimento em natação sustentada se deve à melhor utilização dos nutrientes do alimento, mais do que a um aumento no consumo (Christiansen \& Jobling, 1990; Davison, 1997).

Apesar de os juvenis de matrinxã mantidos em natação sustentada terem consumido mais ração do que os sedentários e atingido pesos semelhantes, a principal diferença no crescimento esteve focalizada nos músculos locomotores. Como esses músculos 
representam até $60 \%$ do peso total dos peixes, qualquer mudança terá uma considerável influência no crescimento deles como um todo (Totland et al., 1987; Davison, 1997). Alguns autores relatam que matrinxã mantido em nado sustentado tem apresentado peso superior, com diferença de até $38 \%$ em relação aos criados em condições sedentárias (Hackbarth \& Moraes, 2006; Arbeláez-Rojas \& Moraes, 2010). A composição corporal de matrinxã criado em nado sustentado a $1,0 \mathrm{CC} \mathrm{s}^{-1}$ apresenta $3 \%$ mais proteína no músculo branco do que exemplares criados em sistema convencional (Arbeláez-Rojas \& Moraes, 2010).

As principais reservas energéticas nos peixes são estocadas no fígado, músculos e, principalmente, ao redor das vísceras, em forma de glicogênio e gordura (Jobling, 2001). Alterações dessas reservas endógenas podem ser determinadas por meio dos índices hepatosomático (IHS) e gorduro-víscero-somático (IGVS), os quais podem indicar o balanço energético nos peixes (Jobling, 2001). Foram observadas variações no IHS, que se refletiram nas adaptações bioquímicas observadas em resposta ao exercício e ao teor proteico da dieta (Tabela 2). Mudanças na composição bioquímica do fígado podem indicar alterações na alimentação, variações ambientais ou migrações reprodutivas. Alterações das reservas hepáticas de glicogênio levam à gliconeogênese (Bombardier et al., 2009). Salmonídeos mantidos em nado sustentado, alimentados com dietas comerciais, apresentam aumento de glicogênio hepático e maior IHS, o que está de acordo com os resultados do presente trabalho.
O aumento do IHS também foi observado em truta Oncorhynchus tshawytscha (Walbaum, 1792), mantida à velocidade de 1,5 CC s${ }^{-1}$ (Kiessling et al., 1994b), e em bacalhau do Atlântico Gadus morhua (L., 1758), exercitado à velocidade de $1,0 \mathrm{CC} \mathrm{s}^{-1}$ (Bjørnevik et al., 2003). O IHS de matrinxã mantido em natação sustentada aumentou 6,5\%, independentemente do nível proteico da dieta. $\mathrm{O}$ teor de glicogênio hepático nesses peixes foi $18 \%$ superior ao dos peixes sedentários. Esse fato pode ter ocorrido em razão da maior eficiência alimentar (Tabela 3), o que indicaria melhoria do estado nutricional dos peixes em nado sustentado, tal como sugerido para outras espécies (Jobling et al., 1993).

Em relação ao sistema de criação, observou-se que peixes mantidos sob natação sustentada depositaram menos gordura visceral do que os sedentários, conforme evidenciaram os menores valores de IGVS (Tabela 2). Os peixes alimentados com $38 \%$ de PB acumularam mais gordura visceral do que os alimentados com $28 \%$ de PB. O IGVS permite acompanhar a deposição e a mobilização da gordura armazenada na cavidade visceral, que refletem as condições nutricionais recentes, o desequilíbrio de nutrientes e o gasto de reservas de lipídios resultante de atividades físicas. Em matrinxã, a velocidade de natação de $1,5 \mathrm{CC} \mathrm{s}^{-1}$ favoreceu a diminuição da gordura visceral. Esse aspecto é importante na criação de peixes em confinamento, por ser inversamente proporcional ao rendimento de carcaça. Espécies reofílicas e de piracema, como o matrinxã, tendem a acumular

Tabela 2. Desempenho e morfometria em juvenis de Brycon amazonicus, submetidos à natação sustentada (NS) ou sedentarismo $(\mathrm{S})$ e alimentados com dois níveis de proteína bruta $(\mathrm{PB})^{(1)}$.

\begin{tabular}{|c|c|c|c|c|c|c|c|c|c|c|c|}
\hline \multirow[t]{3}{*}{ Parâmetro } & \multicolumn{3}{|c|}{$\mathrm{F}$} & \multicolumn{4}{|c|}{ Interação } & \multicolumn{4}{|c|}{ Efeitos principais } \\
\hline & \multirow[t]{2}{*}{ Atividade } & \multirow[t]{2}{*}{ Teor de PB } & \multirow[t]{2}{*}{$\overline{\text { Interação }}$} & \multicolumn{2}{|c|}{$38 \% \mathrm{~PB}$} & \multicolumn{2}{|c|}{$28 \% \mathrm{~PB}$} & \multicolumn{2}{|c|}{ Atividade } & \multicolumn{2}{|c|}{ Teor de PB (\%) } \\
\hline & & & & NS & $\mathrm{S}$ & NS & S & NS & S & 28 & 38 \\
\hline Peso inicial (g) & - & - & - & $30,0 \pm 1,8$ & $29,1 \pm 1,1$ & $28,2 \pm 0,86$ & $30,2 \pm 1,5$ & - & - & - & - \\
\hline Peso final (g) & $24,72 *$ & $4,8^{\text {ns }}$ & $7,28 *$ & $141,9 \pm 4,4 b$ & $134,5 \pm 7,3 b$ & $157,9 \pm 4,2 \mathrm{a}$ & $132,7 \pm 7,9 b$ & 149,9 & 133,6 & 138,1 & 145,3 \\
\hline Taxa crescimento específico & $17,90 *$ & $3,44^{\mathrm{ns}}$ & $13,16^{*}$ & $2,57 \pm 0,09 \mathrm{~b}$ & $2,54 \pm 0,00 \mathrm{~b}$ & $2,82 \pm 0,08 \mathrm{a}$ & $2,46 \pm 0,08 b$ & 2,69 & 2,50 & 2,56 & 2,64 \\
\hline Ganho de peso diário & $36,75^{*}$ & $5,33 *$ & $24,05^{*}$ & $1,78 \pm 0,02 b$ & $1,75 \pm 0,02 b$ & $1,94 \pm 0,05 \mathrm{a}$ & $1,69 \pm 0,05 b$ & 1,86 & 1,72 & 1,82 & 1,76 \\
\hline Conversão alimentar aparente & $56,25^{*}$ & $13,27 *$ & $0,45^{\mathrm{ns}}$ & $1,61 \pm 0,04$ & $1,43 \pm 0,03$ & $1,52 \pm 0,04$ & $1,34 \pm 0,04$ & $1,56 \mathrm{~A}$ & $1,39 \mathrm{~B}$ & $1,43 \mathrm{~B}$ & $1,52 \mathrm{~A}$ \\
\hline Taxa de eficiência proteica & $20,08 *$ & 253,53 & $78,87^{*}$ & $1,75 \pm 0802 b$ & $1,75 \pm 0,02 b$ & $1,94 \pm 0,09 \mathrm{a}$ & $1,69 \pm 0,07 b$ & 2,239 & 2,055 & 2,47 & 1,182 \\
\hline Eficiência alimentar & $45,31 *$ & $0,21^{\mathrm{ns}}$ & $21,08^{*}$ & $0,68 \pm 0,02 b$ & $0,65 \pm 0,02 b c$ & $0,74 \pm 0,02 \mathrm{a}$ & $0,61 \pm 0,02 \mathrm{c}$ & 0,709 & 0,634 & 0,674 & 0,669 \\
\hline Consumo diário de ração (g) & $2,56^{\mathrm{ns}}$ & $0,45^{\mathrm{ns}}$ & $0,13^{\mathrm{ns}}$ & $2,73 \pm 0,20$ & $2,5 \pm 0,20$ & $2,61 \pm 0,20$ & $2,46 \pm 0,20$ & $2,67 \mathrm{~A}$ & $2,48 \mathrm{~A}$ & $2,53 \mathrm{~A}$ & $2,61 \mathrm{~A}$ \\
\hline Fator de condição & $10,54 *$ & $0,38^{\mathrm{ns}}$ & $0,93^{\mathrm{ns}}$ & $1,56 \pm 0,00$ & $1,52 \pm 0,00$ & $1,59 \pm 0,01$ & $1,52 \pm 0,00$ & $1,57 \mathrm{~A}$ & $1,52 \mathrm{~B}$ & $1,55 \mathrm{~A}$ & $1,54 \mathrm{~B}$ \\
\hline Glicogênio & $35,61^{*}$ & $27,21^{*}$ & $17,44^{*}$ & $445,58 \pm 22 \mathrm{a}$ & $421,47 \pm 11 \mathrm{a}$ & $431,58 \pm 33 a$ & $295,06 \pm 20 b$ & 438,58 & 358,27 & 363,32 & 433,53 \\
\hline Índice gorduro-viscero-somático & $9,13 *$ & $5,14^{*}$ & $0,32^{\mathrm{ns}}$ & $3,67 \pm 0,11$ & $3,92 \pm 0,10$ & $3,73 \pm 0,10$ & $4,14 \pm 0,12$ & $3,81 \mathrm{~B}$ & $4,03 \mathrm{~A}$ & $3,84 \mathrm{~B}$ & $4,00 \mathrm{~A}$ \\
\hline Índice hepatossomático & $7,93 *$ & $2,82 *$ & $0,35^{\mathrm{ns}}$ & $1,51 \pm 0,03$ & $1,42 \pm 0,05$ & $1,48 \pm 0,05$ & $1,35 \pm 0,05$ & $1,483 \mathrm{~A}$ & $1,386 \mathrm{~B}$ & $1,405 \mathrm{~B}$ & $1,463 \mathrm{~A}$ \\
\hline
\end{tabular}

${ }^{(1)}$ Médias \pm desvio-padrão seguidas por letras iguais, minúsculas quando há interação e maiúsculas para os efeitos principais, não diferem pelo teste de Tukey, a $5 \%$ de probabilidade. 
gordura no músculo da cavidade visceral e no tecido adiposo mesentérico, antes da época da reprodução, mobilizando-a durante a migração reprodutiva (Bombardier et al., 2009). Os juvenis de matrinxã mantidos em nado sustentado por 60 dias utilizaram, provavelmente, os depósitos de gordura visceral para atender às demandas energéticas do exercício, enquanto o oposto se observou nos peixes sedentários.

Os peixes alimentados com $38 \%$ de $\mathrm{PB}$ apresentaram maior acúmulo de gordura visceral (Tabela 2). Essa resposta pode ser atribuída ao desequilíbrio da relação energia/proteína igual a 14 , nas dietas com $28 \%$ de $\mathrm{PB}$, em comparação àquelas com $38 \%$ de $\mathrm{PB}$. A base fisiológica da demanda de alimento é o suprimento das necessidades energéticas (Lupatsch et al., 2003a). Os peixes alimentados com maior teor de proteína teriam aumentado a ingestão de alimento, para atingir a saciedade e a provisão de suas necessidades energéticas. $\mathrm{O}$ excesso de proteína ingerida e não convertida em massa muscular teria sido convertida em gordura mesentérica, um importante sítio de reserva no matrinxã. Em alevinos de B. orbignyanus, a relação energia/proteína observada para o melhor desempenho é 10,4 (Sá \& Fracalossi 2002).

O estado fisiológico dos peixes, em relação às suas reservas energéticas, tais como glicogênio hepático e gordura corporal, é bem caracterizado pelo fator de condição (FC). Esse índice mostrou que, apesar do

Tabela 3. Comparação de médias por ANOVA, para as atividades específicas ${ }^{(1)}$ de protease ácida (estômago) e alcalina (intestino) de juvenis de matrinxã, submetidos à natação sustentada ou sedentarismo e alimentados com dois níveis de proteína bruta $(\mathrm{PB})^{(2)}$.

\begin{tabular}{lcccc}
\hline Fatores & Estômago & $\begin{array}{c}\text { Cecos } \\
\text { pilóricos }\end{array}$ & $\begin{array}{c}\text { Intestino } \\
\text { anterior }\end{array}$ & $\begin{array}{c}\text { Intestino } \\
\text { posterior }\end{array}$ \\
\hline Tipo de natação (TN) & $52,65^{* *}$ & $5,81^{*}$ & $277,90^{*}$ & $147,68^{* *}$ \\
Nível de PB & $16,75^{* *}$ & 1,20 & $58,95^{* *}$ & $5,99^{*}$ \\
Interação TN x PB\% & $3,41^{\mathrm{ns}}$ & $3,82^{\mathrm{ns}}$ & $7,39^{* *}$ & $0,83^{\mathrm{ns}}$ \\
\hline & & Sistema de criação & \\
Natação sustentada & $1,175 \mathrm{a}$ & $0,318 \mathrm{a}$ & $0,123 \mathrm{a}$ & $0,292 \mathrm{a}$ \\
Sedentários & $1,013 \mathrm{~b}$ & $0,274 \mathrm{~b}$ & $0,072 \mathrm{~b}$ & $0,136 \mathrm{~b}$ \\
\hline & \multicolumn{5}{c}{ Teor de PB na dieta } \\
$28 \%$ & $1,048 \mathrm{~b}$ & 0,286 & $0,087 \mathrm{~b}$ & $0,198 \mathrm{~b}$ \\
$38 \%$ & $1,139 \mathrm{a}$ & 0,306 & $0,112 \mathrm{a}$ & $0,230 \mathrm{a}$ \\
\hline
\end{tabular}

${ }^{(1)}$ As atividades enzimáticas estão expressas em UI por mg de proteína, em que $1,0 \mathrm{UI}$ é a quantidade de enzima capaz de produzir $1 \mu \mathrm{g}$ de tirosina por min. ${ }^{(2)}$ Médias seguidas de letras iguais, nas colunas, não diferem a $5 \%$ de

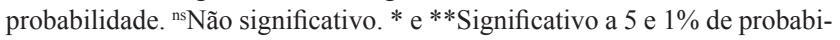
lidade, respectivamente. esforço adicional oriundo da natação sustentada, os peixes estavam bem alimentados. O FC observado ao final do período experimental, nos peixes mantidos em nado sustentado, foi significativamente superior àquele do grupo mantido em sistema sedentário (Tabela 2). Esses dados concordam com os obtidos para ganho de peso e comprimento. O principal objetivo da nutrição animal é maximizar o aproveitamento dos nutrientes da dieta. Com relação às proteínas, a eficácia de seu aporte é diretamente proporcional à sua deposição, a qual resulta em aumento de massa corporal dos peixes. Esse aproveitamento da fração proteica pode ser determinado por meio da taxa de eficiência proteica (TEP), que indica o quanto da PB da dieta foi convertida em massa corporal. Os peixes mantidos em regime de natação sustentada e alimentados com $28 \%$ de PB apresentaram valores maiores de TEP. Esses dados indicam que a combinação desses dois fatores foi a mais efetiva na transformação da proteína da dieta em peso corporal.

A atividade proteolítica total do trato gastrointestinal de matrinxã variou em resposta ao nível de proteína da dieta e ao exercício (Tabela 3). A atividade específica das proteases ácidas e alcalinas aumentou significativamente, em relação à $\mathrm{PB}$ da dieta, e essa resposta foi ainda mais exacerbada nos peixes em natação sustentada. Além disso, a interação entre o sistema de criação e o nível de PB afetou significativamente a atividade proteolítica alcalina (Figura 1). Por conseguinte, os peixes em natação sustentada que receberam a dieta com maior teor de proteína apresentaram maior atividade proteolítica no intestino anterior. $\mathrm{O}$ aumento da atividade proteolítica, no intestino de matrinxã alimentado com níveis crescentes de proteína, já é conhecido (Vieira, 2002). Todavia, ao nosso conhecimento, neste trabalho reporta-se, pela primeira vez, a potencialização dessa atividade enzimática em razão do exercício físico, o que sugere um efeito sinérgico dessas duas variáveis. O desempenho físico demandado pelo exercício, especialmente os de baixa intensidade e longa duração, tem dependência direta do funcionamento do sistema digestivo. Assim, seria esperada uma interação positiva entre a atividade enzimática digestiva e os valores de desempenho, tal como observada no presente trabalho, para os juvenis de matrinxã criados em natação sustentada a $1,5 \mathrm{CC} \mathrm{s}^{-1}$.

A atividade proteolítica inespecífica exibiu caráter adaptativo, não só quanto ao nível proteico da dieta, 
como já relatado, mas também quanto ao exercício. Apesar de ter utilizado protocolo experimental diferente, Bolasina et al. (2006) descrevem resultado semelhante, em trabalho com linguado, Paralichthys olivaceus (Temminck \& Schlegel, 1846), exposto a ambiente de correnteza. Essa atividade aumentada, provavelmente é consequência da maior ingestão de alimento. No entanto, outros processos fisiológicos, como o aumento do fluxo sanguíneo, observado no trato gastrointestinal em peixes exercitados, indicam o aumento do metabolismo em decorrência dos processos simultâneos, alimentação e exercício (Altimiras et al., 2008). Em matrinxã, a atividade proteolítica aumentada em peixes sob natação sustentada, em comparação com os sedentários, resultou em melhor eficiência na digestão da dieta oferecida.

A correnteza da água é um dos principais fatores ambientais atuantes sobre os processos fisiológicos e metabólicos dos peixes (Carter \& Houlihan, 2001). Conforme a intensidade e tempo de exposição à correnteza da água, processos como a digestão enzimática podem exibir ajustes para compensar ou minimizar possíveis efeitos produzidos pelo exercício. Não é de conhecimento dos autores a existência de

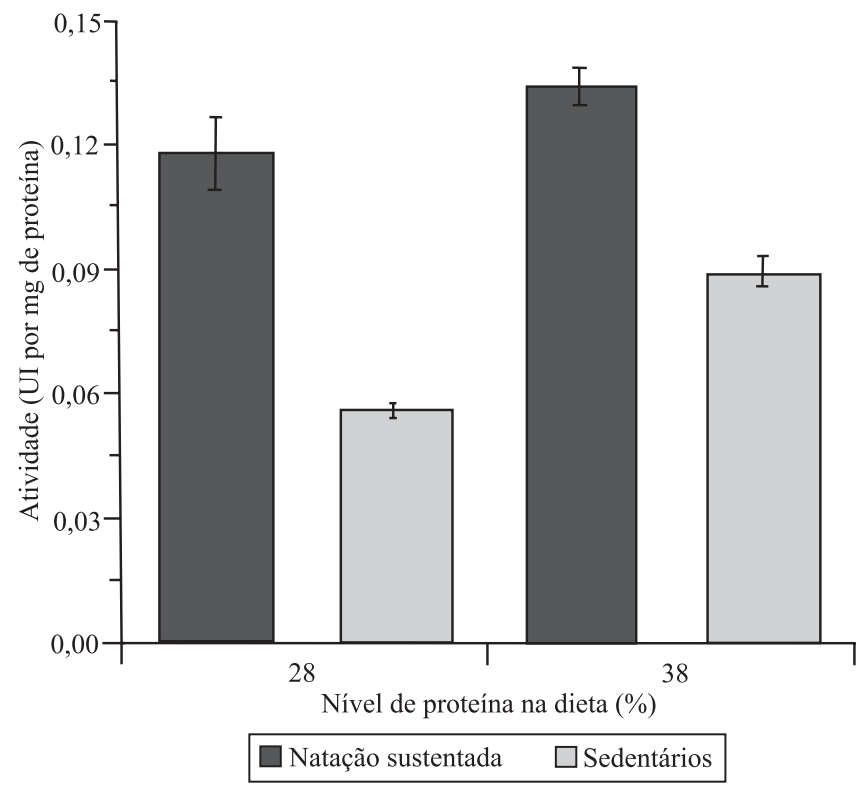

Figura 1. Atividade específica de protease alcalina, em intestino anterior de Brycon amazonicus, submetido à natação sustentada ou sedentarismo, alimentado com dois níveis de proteína bruta. Médias seguidas de letras iguais não diferem, pelo teste de Tukey, a 5\% de probabilidade. As barras representam os valores do desvio-padrão $(n=9)$. trabalhos que descrevam a relação entre o exercício e atividade enzimática digestiva em peixes. Há estudos de nutrição associada ao exercício em mamíferos terrestres, tais como equinos, em que está evidenciada a diminuição do tempo de trânsito intestinal do alimento e aumento do consumo voluntário e da digestibilidade aparente (Orton et al., 1985). Em ratos sob exercícios de longa duração em esteiras, observou-se aumento de colecistocinina, que estimula a secreção das enzimas pancreáticas lipase e amilase (Ohta et al., 1994; Minato et al., 2000). O aumento na atividade proteolítica alcalina, observada nos peixes mantidos em natação sustentada, indica maior capacidade digestiva nesses animais, em comparação aos sedentários. Esses ajustes parecem ser uma adaptação benéfica ao exercício que, nessas condições, poderia ser adotado como alternativa nas atividades de criação. A natação sustentada seria uma maneira natural de estimular o crescimento e trazer maiores benefícios ao produtor, além de aumentar o bem-estar para os peixes, em comparação àqueles criados em condições sedentárias.

\section{Conclusões}

1. Juvenis de matrinxã condicionados ao exercício de natação sustentada e alimentados com $28 \%$ de PB melhoram seu desempenho.

2. A atividade proteolítica total é responsiva a variações nos níveis de $\mathrm{PB}$, e estas respostas são amplificadas pelo exercício.

\section{Agradecimentos}

Ao Conselho Nacional de Desenvolvimento Científico e Tecnológico, pelo apoio financeiro e concessão de bolsa; à Fundação de Amparo à Pesquisa do Estado de São Paulo e à Empresa Brasileira de Pesquisa Agropecuária, pelo aporte de recursos; e a todos os colegas do laboratório de Bioquímica Adaptativa, pelo suporte logístico.

\section{Referências}

ALTIMIRAS, J.; CLAIREAUX, G.; SANDBLOM, E.; FARRELL, A.P.; McKENZIE, D.J.; AXELSSON, M. Gastrointestinal blood flow and postprandial metabolism in swimming sea bass Dicentrarchus labrax. Physiological and Biochemical Zoology, v.81, p.663-672, 2008.

ARBELÁEZ-ROJAS, G.A.; FRACALOSSI, D.M.; FIM, J.L. Body composition of tambaqui, Colossoma macropomum, and 
Matrinxã, Brycon cephalus, when raised in intensive (igarapé channel) and semi-intensive (pond) culture systems. Revista Brasileira de Zootecnia, v.3, p.1059-1069, 2002.

ARBELÁEZ-ROJAS, G.A.; MORAES, G. Interação do exercício de natação sustentada e da densidade de estocagem no desempenho e na composição corporal de juvenis de matrinxã Brycon amazonicus. Ciência Rural, v.39, p.201-208, 2009.

ARBELÁEZ-ROJAS, G.A.; MORAES, G. Optimization of sustaining swimming speed of matrinxã Brycon amazonicus: performance and adaptive aspects. Scientia Agricola, v.67, p.253-258, 2010.

BIDINOTTO, P.M.; SOUZA, R.H.S.; MORAES, G. Hepatic glycogen in eight tropical freshwater teleost fish: a procedure for field determinants of microsamples. Boletim Técnico do CEPTA, v.10, p.53-60, 1997.

BJØRNEVIK, M.; KARLSEN, Ø.; JOHNSTON, I.A.; KIESSLING, A. Effect of sustained exercise on white muscle structure and flesh quality in farmed cod (Gadus morhua L.). Aquaculture Research, v.34, p.55-64, 2003.

BOLASINA, S.; TAGAWA, M.; YAMASHITA, Y.; TANAKA, M. Effect of stocking density on growth, digestive enzyme activity and cortisol level in larvae and juveniles of Japanese flounder, Paralichthys olivaceus. Aquaculture, v.259, p.432-443, 2006.

BOMBARDIER, E.; BOOTH, R.K.; GREEN, H.J.; MCKINLEY, R.S. Metabolic adaptations of oxidative muscle during spawning migration in the Atlantic salmon Salmo salar L. Fish Physiology and Biochemistry, v.36, p.355-365, 2009.

BRANDÃO, F.R.; GOMES, L. de C.; CHAGAS, E.C.; ARAÚJO, L.D. de; SILVA, A.L.F. da. Densidade de estocagem de matrinxã (Brycon amazonicus) na recria em tanque-rede. Pesquisa Agropecuária Brasileira, v.40, p.299-303, 2005.

CARTER, C.G.; HOULIHAN, D.F. Protein synthesis. In: WRIGHT, P.A.; ANDERSON, P.M. (Ed.). Nitrogen excretion. New York: Academic, 2001. p.31-75. (Fish physiology, 20).

CHRISTIANSEN, J.S.; JOBLING, M. The behaviour and the relationship between food intake and growth and juvenile Arctic charr, Salvelinus alpinus L., subjected to sustained exercise. Canadian Journal of Zoology, v.68, p.2185-219, 1990.

CUNNIFF, P. (Ed.). Official methods of analysis of AOAC International. $16^{\text {th }}$ ed. Arlington: AOAC International, 1995. $1117 \mathrm{p}$.

DAVISON, W. The effects of exercise training on teleost fish, a review of recent literature. Comparative Biochemistry and Physiology, Part A, v.117, p.67-75, 1997.

DUBOIS, M.; GILLES, K.A.; HAMILTON, J.K. Colorimetric method for determination of sugars and related substances. Analytical Chemistry, v.28, p.350-358, 1956.

HACKBARTH, A.; MORAES, G. Biochemical responses of matrinxã Brycon cephalus (Gunther, 1869) after sustained swimming. Aquaculture Research, v.7, p.1070-1078, 2006.

HIDALGO, M.C.; UREA, E.; SANZ, A. Comparative study of digestive enzymes in fish with different nutritional habits.
Proteolytic and amylase activities. Aquaculture, v.170, p.267-283, 1999.

HOWES, G. Review of the genus Brycon (Teleostei: Characoidei). London: The British Museum of Natural History, 1982. 47p. (Bulletin of the British Museum of Natural History, 43).

INOUE, L.A.K.A.; SANTOS NETO, C.; MORAES, G. Clove oil as anaesthetic for juveniles of matrinxã, Brycon cephalus (Gunther, 1869). Ciência Rural, v.33, p.943-947, 2003.

JOBLING, M. Nutrient partitioning and the influence of feed composition on body composition. In: HOULIHAN, D.; BOUJARD, T.; JOBLING, M. (Ed.). Food intake in fish. Oxford: Blackwell Science, 2001. p.354-375.

JOBLING, M.; BAARDVIK, B.M.; CHRISTIANSEN, J.S.; JØRGENSEN, E.H. The effects of prolonged exercise training on growth performance and production parameters in fish. Aquaculture International, v.1, p.95-111, 1993.

KIESSLING, A.; HIGGS, D.A; DOSANJH, B.S.; EALES, J.G. Influence of sustained exercise at two ration levels on growth and thyroid function of all-female Chinook salmon (Oncorhynchus tshawytscha) in seawater. Canadian Journal of Fisheries and Aquatic Sciences, v.51, p.1975-1984, 1994.

KRUGER, N.J. The Bradford method for protein quantitation. In: WALKER, J.M. (Ed.). The protein protocols handbook. $2^{\text {nd }}$ ed. New Jersey: Humana, 2002. p.15-21.

LI, X.M.; CAO, Z.D.; PENG, J.L.; FU, S.J. The effect of exercise training on the metabolic interaction between digestion and locomotion in juvenile darkbarbel catfish (Peltebagrus vachelli). Comparative Biochemistry and Physiology, Part A, v.156, p.67-73, 2010.

LUPATSCH, I.; KISSIL, W.M.; SKLAN, D. Comparison of energy and protein efficiency among three fish species gilthead sea bream (Sparus aurata), European sea bass (Dicentrarchus labrax) and white grouper (Epinephelus aeneus): energy expenditure for protein and lipid deposition. Aquaculture, v.225, p.175-189, 2003.

MINATO, K.; SHIROYA, Y.; NAKAE, Y.; KONDO, T. The effect of chronic exercise on the rat pancreas. International Journal of Pancreatology, v.27, p.151-156, 2000.

OHTA, M.; ICHIKAWA, M.; SAZAKI, N.; OKUBO, K.; KYOKO, M.; FUJTA, Y.; MATSUMOTO, M.; FUNAKOSHI, A. Effect of long-term exercise under restricted-feeding on intestinal content of cholecystokinin and on the pancreas in aging rats. Archives of Gerontology and Geriatrics, v.18, p.43-51, 1994.

ORTON, R.K.; HUME, I.D.; LENG, R.A. Effects of level of dietary protein and exercise on growth rates of horses. Equine and Veterinary Journal, v.17, p.381-385, 1985.

PITCHER, J.T.; HART, J.B.P. Fisheries Ecology. London: Chapman \& Hall, 1982. 414p.

SÁ, M.V. do C. e; FRACALOSSI, D.M. Exigência protéica e relação energia/proteína para alevinos de piracanjuba (Brycon orbignyanus). Revista Brasileira de Zootecnia, v.31, p.1-10, 2002. 
TOTLAND, G.K.; KRYVI, H.; JODESTOL, K.A.; CHRISTIANSEN, E.N.; TANGERAS, A.; SLINDE, E. Growth and composition of the swimming muscle of adult Atlantic salmon, (Salmo salar L.) during long-term sustained swimming. Aquaculture, v.66, p.299-313, 1987.
VIEIRA, V.L.P. Estudo de processo digestivo em Brycon cephalus (matrinxã) e Brycon orbignyanus (piracanjuba) alimentados com diferentes teores de proteína: aspectos adaptativos e resposta metabólica. 2002. 94p. Tese (Doutorado) - Universidade Federal de São Carlos, São Carlos.

Recebido em 21 de junho de 2011 e aprovado em 5 de outubro de 2011 